\section{AB0750 INFLUENCE OF AXIAL INVOLVEMENT ON FREQUENCY OF ENTHESITIS AND DACTYLITIS, PATIENTS' REPORTED OUTCOMES AND THEIR FUNCTIONAL CAPACITY. DATA FROM THE RUSSIAN PSORIATIC ARTHRITIS REGISTRY (RU-PSART)}

${ }^{1}$ Gubar Elena*, Elena Loginova ${ }^{1}$, Anastasia Koltakova ${ }^{1}$, Yulia Korsakova ${ }^{1}$,
Tatiana Korotaeva ${ }^{1}$, Evgeny Nasonov ${ }^{1}$, Maria Sedunova ${ }^{2}$, Igor Pristavsky Tatiana Korotaeva ${ }^{1}$, Evgeny Nasonov ${ }^{1}$, Maria Sedunova ${ }^{2}$, Igor Pristavsky ${ }^{2}$, Institute of Rheumatology, Moscow, Russian Federation; ${ }^{2}$ St. Petersburg Clinical Rheumatology Hospital No.25, Rheumatology, St. Petersburg, Russian Federation; ${ }^{3}$ Omsk Regional Hospital, Rheumatology, Omsk, Russian Federation; ${ }^{4}$ Kemerovo Regional Hospital, Rheumatology, Kemerovo, Russian Federation; ${ }^{5}$ Vladivostok Clinical Hospital No.2, Rheumatology, Vladivostok, Russian Federation

Background: The latest data show that axial involvement in psoriatic arthritis (PsA) patients (pts) is associated with significantly worse disease status and widespread impairment of patient-reported outcomes (PRO's) (1).

Objectives: To analyze clinical characteristics and PRO's in PsA pts with and without radiographic sacroiliitis (rSI) in the Russian Psoriatic Arthritis Registry (RU-PsART).I

Methods: 385 pts (M/F-172/213) with PsA according to CASPAR criteria were included in the RU-PSART. Data was collected from 25 rheumatology clinics from various regions of the Russian Federation. Median age 45 (Min 20-Max 80) years (yrs), disease duration 3.4 yrs (4 months-32 yrs). Pts underwent standard clinical examination of PsA activity. All pts were studied for patient global disease activity (PGA) and patients' pain measured by Visual Analogue Scale (VAS), and Health Assessment Questionnaire (HAQ). Physician's global assessment of disease activity (PG) was measured by VAS. The examination included X-ray of sacroiliac joints (pelvic radiographs). rSI was defined as bilateral grade $\geq 2$ or unilateral grade $\geq 3$. Pts were split into two groups (gr.): those with $\mathrm{rSI}$ $[\mathrm{rSI}(+)]$ and those without $\mathrm{rSI}[\mathrm{rSI}(-)]$. Medians and quartiles [Me (Q25; Q75)], [Min; Max], U-test and ORs with $95 \% \mathrm{Cl}$ were performed. All $\mathrm{Cl}$ $>1, p<0.05$ were considered to indicate statistical significance.

Results: gr. $\mathrm{rSI}(+)$ included $214(55.6 \%)$ cases (M/F-106/108), gr. $r S I(-)$ included 171 (44.4\%) cases (M/F-66/105). Median age in gr. $\mathrm{rSI}(+)$ was 45 [Min 20-Max 80] yrs, in gr. rSI(-) it was 46 [Min 21- Max 82] yrs. Significant differences were revealed between gr. $\mathrm{rSI}(+)$ and gr. $\mathrm{rSI}(-)$. In Leeds Enthesitis Index (LEI): in gr. $\mathrm{rSI}(+)$ LEI was 0 [0-2], in gr. rSI(-) it was 0 [0-1] $(\mathrm{p}=0.02)$. In frequency of dactylitis: in gr. $\mathrm{rSI}(+) 71$ pts had dactylitis, 143 did not have; in gr. rSI(-) 32 pts had dactylitis, 139 did not have. OR 2.2 [1.3-3.5]. In PGA: in gr. rSI(+) it was 56.5 [42.370.0], in gr. $\mathrm{rSI}(-)$ it was 50.0 [30.0-60.0] $(\mathrm{p}=0.00)$. In patients' pain: in gr. $\mathrm{rSI}(+)$ it was 50.0 [40.0-70.0], in gr. $\mathrm{rSI}(-)$ it was 50.0 [20.5-58.8] $(\mathrm{p}=0.00)$. In PG: in gr. $\mathrm{rSI}(+)$ it was 54.0 [40.0-69.5], in gr. rSI(-) it was 40.0 [25.5-50.0] $(\mathrm{p}=0.00)$. In HAQ scores: in gr. $\mathrm{rSI}(+)$ it was 1.0 [0.61.5], in gr. $\mathrm{rSI}(-)$ it was 0 [0-2.2] $(\mathrm{p}=0.02)$.

Conclusion: Axial involvement is identified in more than half $(55.6 \%)$ of the PsA pts. The presence of axial involvement in PsA pts is associated with significantly worse disease status as measured by frequency of enthesitis and dactylitis, worse PRO's and with the reduction of patient's functional capacity. Consequently, the diagnostics of axial involvement is critical in clinical practice.

\section{REFERENCES}

[1] P. J. Mease, et al. J Rheumatol 2018;45:1389-96

Disclosure of Interests: ELENA GUBAR: None declared, Elena Loginova Speakers bureau: Novartis, Celgene Corporation, Biocad, Janssen, AbbVie Inc, Anastasia Koltakova: None declared, Yulia Korsakova Speakers bureau: Celgene Corporation, Janssen, Tatiana Korotaeva Consultant for: Pfizer, MSD, Novartis, AbbVie, Celgene, Biocad, Janssen, UCB, Lilly and Novartis-Sandoz, Speakers bureau: Pfizer, MSD, Novartis, AbbVie, Celgene, Biocad, Janssen, UCB, Lilly and Novartis-Sandoz, Evgeny Nasonov Speakers bureau: Pfizer, Inc., MSD, Novartis, AbbVie Inc., Celgen Corporation, Biocad, Janssen, UCB, Inc., Maria Sedunova: None declared, Igor Pristavsky: None declared, Irina Umnova: None declared, Irina Bondareva: None declared, Snezana Kudishina: None declared DOI: 10.1136/annrheumdis-2019-eular.1691

\section{AB0751 \\ ASSOCIATION OF AXIAL INVOLVEMENT WITH MORE SEVERE DISEASE: HIGH DISEASE ACTIVITY, SEVERE PERIPHERAL ARTHRITIS AND WORSE SKIN LESION. DATA FROM THE RUSSIAN PSORIATIC ARTHRITIS REGISTRY (RU-PSART)}

${ }^{1}$ Gubar Elena", Elena Loginova', Anastasia Koltakova', Yulia Korsakova', Tatiana Korotaeva ${ }^{1}$, Evgeny Nasonov ${ }^{1}$, Maria Sedunova $^{2}$, Igor Pristavsky ${ }^{2}$ Irina Umnova ${ }^{3}$, Irina Bondareva ${ }^{4}$, Snezana Kudishina ${ }^{5}{ }^{1}$ Nasonova Research Institute of Rheumatology, Moscow, Russian Federation; ${ }^{2}$ St. Petersburg Clinical Rheumatology Hospital No.25, Rheumatology, St. Petersburg, Russian Federation ${ }^{3}$ Omsk Regional Hospital, Rheumatology, Omsk, Russian Federation; ${ }^{4}$ Kemerovo Regional Hospital, Rheumatology, Kemerovo, Russian Federation; ${ }^{5}$ Vladivostok Clinical Hospital No.2, Rheumatology, Vladivostok, Russian Federation

Background: The latest data show that axial involvement in psoriatic arthritis (PsA) patients (pts) is associated with significantly more severe disease status (1)

Objectives: To analyze, in clinical practice, disease activity and characteristics of PsA pts with and without radiographic sacroiliitis ( $\mathrm{rSI}$ ).

Methods: 385 pts (M/F-172/213) with PsA according to CASPAR criteria were included in the RU-PsART. Data was collected from 25 rheumatology clinics from various regions of the Russian Federation. Median age 45 (Min 20-Max 80) years (yrs), disease duration 3.4 yrs (4 months-32 yrs). Pts underwent standard clinical examination of PsA activity. Disease activity was measured by DAPSA, DAS28, BASDAI. The examination involved HLA B27 antigen status and X-ray of sacroiliac joints (pelvic radiographs). $\mathrm{rSI}$ was defined as bilateral grade $\geq 2$ or unilateral grade $\geq 3$. Skin lesion severity was evaluated in terms of body surface area (BSA) affected, and Psoriasis Area Severity Index (PASI). When BSA was $\geq 3 \%$, PASI was calculated. Pts were split into two groups (gr.): those with $\mathrm{rSI}[\mathrm{rSI}(+)]$ and those without $\mathrm{rSI}[\mathrm{rSI}(-)]$. Gr. $\mathrm{rSI}(+)$ included $214(55.6 \%)$ cases (M/F-106/108), gr. rSI(-) $171(44.4 \%)$ cases (M/F- 66/ 105). Median age in gr. rSI(+) was 45 [Min 20-Max 80] yrs, in gr. rSI(-) it was 46 [Min 20-Max 82] yrs. Medians and quartiles [Me (Q25; Q75)], [Min; Max], U-test and ORs with $95 \% \mathrm{Cl}$ were performed. All $\mathrm{Cl}>1, \mathrm{p}$ $<0.05$ were considered to indicate statistical significance.

Results: Significant differences were revealed between gr. $\mathrm{rSI}(+)$ and gr. rSI(-). In HLA-B27 antigen status: in gr. $\mathrm{rSI}(+)$ it was positive in 62 pts, negative in 64 pts, while in gr. rSI(-) it was positive in 26 pts, negative in 52 pts. OR 1.9 [1.1-3.5]. In tender joint count (TJC): in gr. $\mathrm{rSI}(+$ TJC was 9 [14-18], in gr. $r S I(-)$ it was 6 [3-12] $(\mathrm{p}=0.02)$. In disease activity measured by DAPSA: in gr. $\mathrm{rSI}(+)$ DAPSA was 28.40 [15.6543.65], in gr. $\mathrm{rSI}(-)$ it was 20.0 [12.45-30.0] $(\mathrm{p}=0.00)$. In DAS28: in gr. $\mathrm{rSI}(+)$ DAS28 was 4.3 [3.3-5.6], in gr. $\mathrm{rSI}(-)$ it was 4.1 [3.0-4.9] $(\mathrm{p}=0.02)$.]. In disease activity measured by BASDAl: in gr. $\mathrm{rSI}(+)$ BASDAl was $1.6[0-5.1]$, in gr. $\mathrm{rSI}(-)$ it was $0[0-4.5](\mathrm{p}=0.00)$. In frequency of erosive radiographic arthritis of feet: in gr. $\mathrm{rSI}(+) 58$ pts had erosive arthritis of feet, 156 did not have, while in gr. rSI(-) 29 pts had erosive arthritis of feet, and 142 did not have. OR 1.8 [1.1-3.0]. In more extensive skin lesion area: in gr. $\mathrm{rSI}(+) \mathrm{BSA}<3 \%$ had $120 \mathrm{pts}$, BSA $>3 \%$ had 94 pts; while in gr. rSI(-) BSA $<3 \%$ had 141 pts, BSA $>3 \%$ had 57 pts. OR 0.6 [0.4-0.97]. In CRP: in gr. $\mathrm{rSI}(+) \mathrm{CRP}$ was 0.9 [0.42.2] $\mathrm{mg} / \mathrm{dll}$, in $\mathrm{gr}$. $\mathrm{rSI}(-)$ it was $0.8[0.3-1.3] \mathrm{mg} / \mathrm{dl}(\mathrm{p}=0.03)$.

Conclusion: Axial involvement in PSA patients is associated with HLAB27 positivity. Patients with axial involvement have significantly worse disease status as measured by disease activity and a higher CRP level; they are more likely to have more severe (erosive) peripheral arthritis and more extensive skin lesion area. Early detection of axial involvement is critical for choice of treatment approach and good prognosis.

\section{REFERENCE}

[1] P. J. Mease, et al. J Rheumatol 2018;45:1389-96

Disclosure of Interests: ELENA GUBAR: None declared, Elena Loginova Speakers bureau: Novartis, Celgene Corporation, Biocad, Janssen, AbbVie Inc, Anastasia Koltakova: None declared, Yulia Korsakova Speakers bureau: Celgene Corporation, Janssen, Tatiana Korotaeva Consultant for: Pfizer, MSD, Novartis, AbbVie, Celgene, Biocad, Janssen, UCB, Lilly and Novartis-Sandoz, Speakers bureau: Pfizer, MSD, Novartis, AbbVie, Celgene, Biocad, Janssen, UCB, Lilly and Novartis-Sandoz, Evgeny Nasonov Speakers bureau: Pfizer, Inc., MSD, Novartis, AbbVie Inc., Celgen Corporation, Biocad, Janssen, UCB, Inc., Maria Sedunova: None declared, Igor Pristavsky: None declared, Irina Umnova: None declared, Irina Bondareva: None declared, Snezana Kudishina: None declared DOI: 10.1136/annrheumdis-2019-eular.1570 